Prepared for the U.S. Department of Energy under Contract DE-AC05-76RL01830

\title{
A Short Assessment of Select Remediation Issues at the Russian Research Center-Kurchatov Institute, Moscow, Russia
}

\author{
R Gephart
}




\title{
DISCLAIMER
}

This report was prepared as an account of work sponsored by an agency of the United States Government. Neither the United States Government nor any agency thereof, nor Battelle Memorial Institute, nor any of their employees, makes any warranty, express or implied, or assumes any legal liability or responsibility for the accuracy, completeness, or usefulness of any information, apparatus, product, or process disclosed, or represents that its use would not infringe privately owned rights. Reference herein to any specific commercial product, process, or service by trade name, trademark, manufacturer, or otherwise does not necessarily constitute or imply its endorsement, recommendation, or favoring by the United States Government or any agency thereof, or Battelle Memorial Institute. The views and opinions of authors expressed herein do not necessarily state or reflect those of the United States Government or any agency thereof.

\author{
PACIFIC NORTHWEST NATIONAL LABORATORY \\ operated by \\ BATTELLE \\ for the \\ UNITED STATES DEPARTMENT OF ENERGY \\ under Contract DE-AC05-76RL01830
}

Printed in the United States of America

Available to DOE and DOE contractors from the

Office of Scientific and Technical Information,

P.O. Box 62, Oak Ridge, TN 37831-0062;

ph: (865) 576-8401

fax: $(865) 576-5728$

email: reports@adonis.osti.gov

\footnotetext{
Available to the public from the National Technical Information Service, U.S. Department of Commerce, 5285 Port Royal Rd., Springfield, VA 22161 ph: (800) 553-6847 fax: $(703) 605-6900$

email: orders@ntis.fedworld.gov

online ordering: http://www.ntis.gov/ordering.htm
}

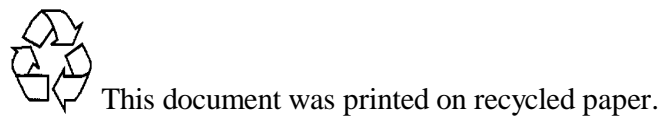




\section{A Short Assessment of Select Remediation Issues at the Russian Research Center- Kurchatov Institute, Moscow, Russia}

R Gephart

June 2007

Prepared for the U.S. Department of Energy under Contract DE-AC05-76RL01830

Pacific Northwest National Laboratory

Richland, Washington 99352 


\title{
A Short Assessment of Select Remediation Issues at the Russian Research Center-Kurchatov Institute, Moscow, Russia
}

\author{
by \\ Roy Gephart
}

June 21, 2007

The Russian Research Center-Kurchatov Institute (RRC-KI) is the leading institute in the Former Soviet Union devoted to military and civilian nuclear programs. Founded in 1943 in the outskirts of Moscow, this 100 hectare site of nearly undeveloped, prime real estate is now surrounded by densely populated urban and business districts. Some public housing adjoins the site's outer perimeter. Today there are growing concerns over the public safety and environmental security of the site resulting from increasingly obsolete nuclear facilities and a legacy of inadequate waste management practices that resulted in contaminant releases and challenging remediation problems. In addition, there is growing worry over the presence of nuclear facilities within urban areas creating potential targets for terrorist attacks.

During our visit to RRC-KI, officials shared that the useful lifetime for all onsite reactors is nearly complete and the Institute is working toward decommissioning those reactors and removing all spent fuel by 2015. This will be coordinated with completing other facility and environmental remediation activities. Cleanup schedules are funding dependent.

Based upon meetings with RRC-KI staff and reading information about the history and remediation of contamination at the site, the following comments are offered:

Site Inventory of Nuclear Material and Waste: The master plan for remediation of RRC-KI should contain an inventory of the nuclear material and waste remaining onsite. This permits decision-makers to understand potential radiological and chemical risks as well as changes in risk profiles and dose rates resulting from remediation work. Written records, interviews with former workers, extrapolations, and new targeted site investigations form the basis for these inventories. Constructing such an inventory is challenging because of incomplete and sometimes conflicting data. The U.S. Department of Energy has faced similar challenges at their nuclear material production, weapons manufacturing, and testing sites.

This inventory could include, for example, information quantifying damaged/un-damaged experimental spent fuel elements, buried waste, soil and groundwater contamination, surface facility hazards, and orphaned radioactive sources or scattered contaminated spots. Such knowledge assists decision-makers in building factual cases for funding site remediation programs. According to the Government of Moscow’s Resolution No. 642 “On Speeded-up D\&D of Radiation Hazardous Facilities at RRC KI,” the goal of 
rehabilitation activities are to "eliminate all potentially hazardous sources of radiation that may produce adverse environmental effects, and to transform RRC KI into a secure and safe nuclear research center within the Moscow city limits" (Volkov et al 2003). Maintaining an up-to-date material and waste inventory is essential for achieving this resolution.

Underground Water Pipes and Drainage Systems: Rastorguev et al (2005) spoke of a groundwater level rise averaging 3 meters plus changes in groundwater flow directions and peak strontium-90 activities in the shallow aquifer beneath RRC-KI taking place between the late 1980s and the early 1990s. The report continued by stating these changes were likely attributed to "leakage from the city sewer that crosses the radwaste disposal site" resulting in the partial submergence of some buried waste sites and flushing out of contamination. Volkov et al (2003) wrote that the Institute's sewerage system has "undergone no repairs" since construction, surveys have uncovered ruptured pipelines and the city's sewerage system, apparently crossing the site, is a potential "source of adverse environmental impacts" that could cause heavy flooding of the site. These are serious concerns in efforts to minimizing subsurface contaminant migration off the RCC-KI site.

Consideration should be given to testing the structural integrity of key water and waste pipelines, abandoning and grouting those of questionable integrity or those of "defunct branches" (Volkov et al 2003) and installing new lines as necessary. Attention should also be given to RRC-KI installing its own water drainage system to intercept, control, and treat (if necessary) water run-off especially during torrential-downpours when the potential for re-suspension of surface contamination is greatest. This would address one of the major uncertainties in the modeling of onsite hydrologic conditions and estimating off-site radiation doses through lessening a major source of contaminant spread as well as potential changes to groundwater flow patterns and rates. These recommendations require the application of standard engineering practices common to municipalities and industries.

Contaminant Barriers: Volkov et al (2007) reported that the use of zeolites and apatites in permeable subsurface barriers to absorb $\mathrm{Sr}^{90}$ or a mixture of sulphuric and phosphoric acids to leach $\mathrm{Cs}^{137}$ from underground sediments was too expensive and experimental for application at RRC-KI's underground waste repositories. Nonetheless, continued examination of such innovative technologies or the use of surface engineered barriers to control water infiltration (and thus radionuclide migration) is encouraged.

Consideration should be given to examining the feasibility of site-tailored surface engineered barriers such as installed at the Hanford Site, Washington State. Built in 1994, the Hanford barrier covers 2 hectares and is constructed from multiple layers of natural sediments and man-made materials to control moisture, plant, and animal entry while minimizing erosion and moisture infiltration even under extreme storm events. Such barriers are nearly maintenance free for hundreds of years and would also control the suspension of contaminated dust. 
In addition, a $90 \mathrm{~m}$ long permeable subsurface reactive test barrier using apatite sequestration to inhibit the migration of $\mathrm{Sr}^{90}$ contaminated groundwater flow into the nearby Columbia River is also being installed at the Hanford Site. Such technology might be applicable to controlling the spread of the $\mathrm{Sr}^{90}$ plume beneath RRC-KI.

Excavation of Waste Repositories: Between 2003 and 2006, 3,400 $\mathrm{m}^{3}$ of solid radwaste was excavated from ten old subsurface concrete-waste repositories at RRC-KI.

Conventional and modified construction equipment was used to access, remove, and repackage waste for onsite disposal or offsite shipment to MosNPO “Radon.” Radiation shielded areas were built for robotic waste retrieval when intermediate to highly radioactive materials were uncovered. Studies reported in Volkov et al (2007) suggested that rapid removal of these repositories would be more cost effective than constructing engineered barriers and would accelerate the removal of subsurface contamination sources. The recommended remediation approach appeared reasonable though concerns are raised over some observations of worker safety.

For comparison, I will use a somewhat analogous, though non-urbanized example to the RRC-KI radwaste repository removal---the Accelerated Retrieval Project in Pit 4 at the Idaho National Engineering and Environmental Laboratory (INEEL) in the state of Idaho. Pit 4 cleanup involves construction of a tent-like enclosure covering the entire low-level and transuranic waste burial site. This fully enclosed all excavation equipment and workers. Water spray was sometimes used to suppress dust during the warmer months at the RRC-KI site. Otherwise most remediation was conducted in the open air. All workers inside the Pit 4 enclosure wore fully protective, tape-sealed protective clothing plus fullface filtered masks. Pictures of the RRC-KI waste removal frequently showed workers without hardhats or particle masks and wearing loose fitting street-type clothing. While visiting RRC-KI on June 8, 2007, and observing solid LLW removal using heavy equipment, onsite workers were lifting pipes and other heavy objects overhead and stirring dust. However, basic safety equipment appeared missing — no hardhats, no particle masks, and minimal dust suppressing using periodic water spray. Nearby residences (perhaps 100 meters away) went unprotected and perhaps uninformed of cleanup activities.

Volkov et al (2007) wrote that detection of high-level waste fragments in the solid waste was accomplished using gamma counters/cameras with a signal display on an operator's monitor. Questions arise about the potential for acute worker exposure between the time of fragment detection and use of protective roof shielding and robotics for further material handling. Based upon available information, concerns also exist about the effectiveness of air sampling for alpha- and beta-bearing aerosols suspended around remediation sites when sampling filters are taken to a laboratory for spectrometric and radiochemical analyses before potential worker exposures are recognized as well as the potential need for increased dust abatement implemented.

The collection and treatment of waste water created when washing trucks removing solid waste and debris from surface excavations before traveling on public roads is applauded. 
Groundwater Modeling and Environmental Monitoring: Existing hydrologic modeling are not based on "very rigorous site-specific features" and are, therefore, thought useful for a "first approximation" and inference of flow and transport estimates (Novikov et al, 2005; Novikov 2007). Missing information was obtained using computational-analytical methods. There is a need for more site-specific information on such parameters as sediment hydraulic conductivity, water run-off, hydraulic heads, soil moisture, water infiltration, and the physio-chemical characteristics of buried waste and subsurface contaminants to validate computational models, reduce modeling uncertainty, and more reliably use modeling results to predict present and future flow system behavior. Knowing the hydraulic properties and distributions of highly reworked, nonuniform shallow soil and rubbish mixtures (e.g., from past building demolitions, sediment excavations, ravine filling) discarded over the years is critical because they could dominate water infiltration within contaminated areas. Novikov (2007) notes the permeability of these deposits "was not studied." Based upon available data, have alternative though equally valid flow and transport models been developed?

Consideration should be given to the installation of soil lysimeters for quantifying water infiltration and low-volume (to minimize water extraction) hydraulic tests conducted for measuring sediment permeability. Hydraulic head distribution maps would also be useful to model lateral and vertical flow potentials. Rastorguev et al (2005) stated that water level observations in boreholes have been discontinued except inside wells drilled since 2002-2003. Based upon information reported in Novikov (2007), Rastorguev et al (2005), and Volkov et al (2003), there appears to be 17 to 30 boreholes used for water sampling. The actual number was unclear. Are water samples drawn from different subsurface horizons to identify the lateral and vertical extent of groundwater contamination and offsite migration?

A sustained commitment to long-term environmental monitoring at select sites to establish radiation exposure baselines is necessary to quantify environmental risks and to gain benefits from site remediation efforts.

This writer assumes that periodic groundwater and environmental monitoring reports are published. These would include, for example, contaminant distributions, points of dosimetric monitoring and environmental sampling, plus average and maximum worker and public health effective dose equivalents from exposure to RRC-KI contaminants. It would be useful to report the distribution of environmental risks the public receives from the various pathways--water, air, and food. Such information enables decision-makers to focus cleanup efforts where the greatest risk reduction benefits would take place.

Public Involvement: Novikov (2007) addresses the issue of reducing "public anxiety" about radioactive releases from RRC-KI. This concern was also noted in the presentation given by Volkov on June 5, 2007, as well as in other talks discussing remediation progress at contamination sites across Russia. However, few specifics describing stakeholder engagement were provided. Nearly 30 years of experience in the United States implementing federal waste management and cleanup regulations under the Resource Conservation and Recovery Act (RCRA) and the Comprehensive 
Environmental Response, Compensation, and Liability Act (CERCLA) has demonstrated a strong correlation between public acceptance of waste cleanup actions and a lowering of public concerns with their degree of involvement in the decision-input process. Examples of successful actions for RRC-KI officials to explore include (a) open "round table" discussions with stakeholders where information is provided and public concerns taken seriously, (b) publication of easily understood brochures and web-based information sources summarizing site history, monitoring results, and cleanup actions, (c) independent public or environmental group monitoring of the environment (e.g., water, air, radiation levels) outside RRC-KI boundaries, (d) site tours for the public and news media, and (e) formation of an advisory committee representing public, business, city government, and other interests.

Managing Institutional Memory: Institutional memory about site history, waste inventories, and remediation efforts are easily lost as contaminated sites are remediated and workers retire or attain other jobs. This could be particularly true as pressure mounts to use the Institute's land for urban development purposes. It is recommended that RRCKI create a permanent, comprehensive, and archival data management and record keeping system in an accessible form and format to ensure future site operators or owners understand, for example, what cleanup actions were carried out, why those actions were selected, monitoring results, health and safety records and what contaminants remain onsite. Otherwise, future generations will struggle to reconstruct today's cleanup decisions and to understand the potential environmental risks left behind.

The loss of institutional memory can be rapid. For example, in the United States, within two years after the chemical waste site of Love Canal in New York State was sold, houses and a school were built atop the site though the transfer deed specifically identified potential health hazards. Years later a public emergency was declared because of illnesses, odors, and contamination seeping from the ground.

\section{References:}

Volkov, V.G., Zverkov Yu. A., Semenov S.G., Chesnokov A.V., and Shisha A.D., "Remediation of Contaminated Facilities at RRC 'Kurchatov Institute;'” 14 page paper given to the U.S. National Academy of Sciences for review at the International Workshop "Cleaning Up Sites Contaminated with Radioactive Materials," Moscow, Russia, June 4-6, 2007.

Novikov, Vladimir (editor), “The Nuclear Legacy in Urbanized Areas: Generic Problems and the Moscow Case Study,” International Institute for Applied Systems Analysis, Laxenburg, Austria, RR-07-001, March 2007.

Rastorguev, A., K. Buharin, V. Volkov, D. Tsurikov, Yu. Zverkov, I. Rastorguev, and E. Volkova. "Prognosis of Radionuclide Contamination Spreading on the Site of Temporary Waste Storage of RRC 'Kurchatov Institute,'” EDP Sciences, Supplement 1, vol. 40, S367-370, 2005. 
Novikov, V.M., V.V. Lagutov, T.G. Sazykina, Yu.E. Gorlinskii, O.A. Nikol’skii, and V.I. Pavlenko, "Assessment of the Effect of Temporary Storage Sites for Radioactive Wastes on the Territory of the Russian Science Center Kurchatov Institute on the Population and the Environment,” Atomic Energy, Vol 99, No 2, pages 588-595, 2005.

Volkov V.G., N.N. Ponomarev-Stepnoi, E.S. Melkov, E.P. Ryazantsev, V.S. Dikarev, G.G. Gorodetsky, Yu.A. Zverkov, V.V. Kuznetsov, and T.I. Kuznetsova, "Status of Activities on Rehabilitation of Radioactively Contaminated Facilities and the Site of Russian Research Center 'Kurchatov Institute,”' Waste Management 2003, Tucson, Arizona, February 23-27, 2003. 